\title{
From Boom til Bust: How Loss Aversion Affects Asset Prices
}

\author{
Arjan Berkelaar* Roy Kouwenberg \\ Econometric Institute Report EI2000-21/A \\ May 10,2000

$\begin{aligned} \text { Econometric Institute } & \text { Department of Finance } \\ \text { Faculty of Economics } & \text { Faculty of Economics } \\ \text { Erasmus University Rotterdam } & \text { Erasmus University Rotterdam } \\ \text { P.O.Box 1738, 3000 DR Rotterdam } & \text { P.O.Box 1738, 3000 DR Rotterdam } \\ \text { The Netherlands } & \text { The Netherlands } \\ \text { Tel.nr.: }+31104082388 & \text { Tel.nr.: }+31104082388\end{aligned}$

Abstract

In 1996 Alan Greenspan warned that stock prices were "unduly escalated" and reflected "irrational exuberance". In this paper we describe an economy that can support a prolonged surge of asset prices, accompanied by a sharp increase of volatility. We study an equilibrium model where some agents are risk averse while others have loss averse preferences over wealth, according to prospect theory. We derive closed-form solutions for the equilibrium prices. In good states of the world, the loss averse investors with wealth above the threshold are momentum traders, thereby pushing prices far above the level in the benchmark economy. In moderately bad states of the world, the loss averse investors are contrarian, and equilibrium prices are kept relatively high and stable. Finally in extremely bad states, the loss averse investors are forced to retreat from the stock market in order to avoid bankruptcy, resulting in a sharp price drop.

Keywords: asset pricing, equilibrium, behavioral finance, loss aversion.

JEL Classifications Codes: G11,G12.

\footnotetext{
${ }^{*}$ Corresponding author: Erasmus University Rotterdam, Econometric Institute, P.O. Box 1738, 3000 DR Rotterdam, The Netherlands. Tel.nr.: +31-104082388, Fax.nr.: +31-104089162, Email: berkelaar@few.eur.nl
} 


\section{Introduction}

In December 1996 chairman of the Federal Reserve, Alan Greenspan, warned investors that stock prices were "unduly escalated" and reflected "irrational exuberance". After these comments prices fell temporarily, but the market soon picked up its momentum again. It seems that the irrational and exuberant investors were very reluctant to abandon the 'escalator': the US stock market, represented by the S\&P 500 , has increased by $31 \%, 27 \%$ and $20 \%$ annually in the years following 1996. During the same period, another remarkable trend was the steady increase of market volatility. For example, the percentage of trading days with absolute market returns over $1 \%$ has increased from $13.9 \%$ in 1996 , to $29.6 \%, 28.8 \%$ and $37.2 \%$ in 1997,1998 and 1999 respectively.

Clearly, these facts present a serious challenge to traditional economic models, based on rational expectations, utility from consumption and risk averse behavior. Within this class of models rapidly increasing prices and high levels of volatility are simply impossible, given the mild increase of dividends and aggregate consumption during the last decades. In this paper we propose an equilibrium model that retains all the assumptions of the traditional approach, except that we introduce agents with loss aversion over wealth, according to prospect theory of Kahneman \& Tversky (1979). We derive closed-form solutions for the equilibrium prices and find that an economy with loss averse investors can support a prolonged surge in asset prices, accompanied by a sharp increase of volatility.

Prospect theory was proposed by Kahneman \& Tversky (1979) as a descriptive model for decision making under uncertainty, given the strong violations of the traditional utility paradigm observed in practice. In experiments Kahneman \& Tversky (1979) found that people are concerned about changes in wealth, rather than the level of wealth itself. Moreover, individuals treat gains and losses relative to their benchmark differently: the pain of a loss is felt much more than the payoff of an equivalent gain. Furthermore, in the domain of gains people are risk averse, while they become risk seeking in the domain of losses.

Kahneman and Tversky quantified these empirical findings in prospect theory: individuals maximize an S-shaped value function, which is convex for losses and concave for gains relative to the benchmark (or threshold). We denote agents who maximize this value function as 'loss averse'. The optimal investment strategy of loss averse investors and the impact of these strategies on equilibrium prices are obviously relevant for the field of financial economics. However, a complete economic analysis has been hampered by the odd shape of the value function: it does not possess the standard mathematical properties of concavity and differentiability. Hence, traditional optimization methods can not be applied to solve the investment problem.

Recently however, Berkelaar \& Kouwenberg (2000) solved the investment problem of loss averse investors in complete markets. As might be expected, the results of Berkelaar \& Kouwenberg (2000) show that loss averse agents prefer more risky assets if their wealth increases above the benchmark. Due to their risk seeking attitude towards losses, the loss averse agents also increase their risky asset holdings if wealth drops below the benchmark. In this case the loss averse agents aim to maximize the probability of beating the benchmark. We can summarize these results as follows: loss averse agents are momentum traders above their threshold (buy if prices go up) 
and contrarians below (buy if prices go down).

Berkelaar \& Kouwenberg (2000) consider a partial equilibrium setting: the asset prices are given exogenously and not influenced by the trading activities of the loss averse agents. In this paper we study the effect of loss averse investors in an equilibrium setting: markets have to clear and prices are determined endogenously. Our continuous-time economy is populated by a group of normal risk averse agents and a group of loss averse agents. We assume that all investors in the economy have a power utility function over intertemporal consumption. The normal agents also have power utility over terminal wealth at the planning horizon, while the loss averse agents maximize the prospective value of terminal wealth.

We first show that the riskfree rate and the market price of risk (or Sharpe ratio) are constant in this economy, due to the identical utility function over intertemporal consumption for both groups of agents. This corresponds to the situation in a benchmark economy with normal agents only, and hence loss aversion does not influence the riskfree rate and the Sharpe ratio. Next we derive a closed-form solution for the equilibrium price of the risky asset, also denoted as the stock. In sharp contrast to the interest rate, the stock price is quite different in the presence of loss averse agents.

As wealth is rising above the threshold, the loss averse investors become less risk averse and drive up the stock price by following a momentum strategy. Hence, in good states of the world the equilibrium stock price is much higher than in a benchmark economy with normal agents only. Simultaneously, the stock price becomes increasingly sensitive to dividend changes, which is reflected in an increasing level of volatility. The expected return on stocks is also an increasing function of the state of the world, given the constant market price of risk. Consequently, a booming market is quite likely if the wealth of the loss averse agents ends up above their threshold.

In bad states of the world, where the wealth of the loss averse agents falls below the threshold, the equilibrium price is no longer affected by momentum trading. The loss averse agents switch to a contrarian strategy, as they are aiming to beat the threshold. Consequently, they support the falling price if the state of the world gets worse. The price level is stabilized, at a relatively high level compared to the benchmark economy. The volatility and mean return are low. Eventually however, at some very bad state of the world, the loss averse agents run into solvency problems and can no longer support the price level. From that point onwards the stock price drops down rapidly, while volatility jumps up.

Summarizing, the equilibrium price in an economy with loss averse agents shows an interesting variety of patterns, ranging from boom til bust. Our model may explain a number of known empirical facts, that are hard to explain in the traditional consumption-based framework. For example, the equity premium in our model is time-varying. In bad states of the world prices tend to bounce back up, as loss averse agents with wealth below the threshold support the market. In good states of the world, prices tend to drift upwards even faster due to the decreasing risk aversion of loss averse agents with wealth above the threshold.

It is precisely this mean-averting force of decreasing risk aversion that might explain the "un- 
duly escalated" stock prices observed by Alan Greenspan in 1996. Moreover, the subsequent rally of stock prices and rapidly increasing volatility in 1997, 1998 and 1999 are consistent with the equilibrium effects of loss aversion found in this paper. Earlier papers by Campbell \& Cochrane (1999) and Barberis, Huang \& Santos (2000) have already pointed out that a model with (stochastically) varying risk aversion can increase the volatility of stock returns, relative to the underlying consumption data. As investors want to be compensated for the increased volatility, this also raises the expected excess return on stocks, hence resolving the equity premium puzzle.

There is an interesting connection between our model and the multi-period, infinite horizon model of Barberis et al. (2000). One can interpret our setting as a detailed, one-period snapshot of their multi-period aggregate model. As the model of Barberis et al. (2000) includes multiple evaluation dates, the loss averse investors have to update their benchmark level each period. The main conclusion of Barberis et al. (2000) is that a sluggish updating rule for the benchmark level will increase the volatility of the stock returns. We confirm in this paper that loss averse investors who are ahead of their benchmark indeed drive up the stock price, the mean return and volatility.

Apart from this supporting role in the equity premium discussion, our paper makes a clear contribution to the financial-economic literature itself. We provide closed-form solutions for the equilibrium prices in an economy with heterogeneous agents, whereas Barberis et al. (2000) have to rely on aggregation, a piecewise linear approximation of the value function and simulations in order to calculate asset prices. We provide a detailed micro-economic analysis of the effects of loss aversion and heterogeneity on asset prices, based on our closed form solutions.

Other literature on loss aversion and asset pricing includes Benartzi \& Thaler (1995) and Gomes (2000). The pioneering work of Benartzi \& Thaler (1995) introduces the concept of loss aversion in an investment context and addresses the equity premium puzzle. They rely on a partial equilibrium setting and numerical solutions. Gomes (2000) also analyzes the effect of loss aversion in a partial equilibrium setting. Gomes (2000) solves a one-period model with two states of the world completely and relies on simulations in more general settings. Moreover, he calculates equilibrium prices numerically in a market microstructure model without consumption, production or dividends.

The outline of the paper is as follows. In Section 2 we introduce our continuous-time economy, inhabited by normal and loss averse agents. We present the optimal consumption and investment policies of the agents and state the market clearing conditions. In Section 3 we derive closedform solutions for the interest rate, market price of risk and stock price in the economy. We analyze the main properties of the equilibrium prices. In Section 4 we investigate the additional effect of differences in initial wealth and thresholds among the loss averse agents. We discuss the relevance of our results for the literature on the equity premium puzzle in Section 5. Finally, Section 6 summarizes and concludes the paper. 


\section{Economic Setting}

\subsection{The Economy}

In this section we formulate the Lucas (1978) pure-exchange economy in a continuous-time framework. We consider a finite horizon, $[0, T]$, economy, which is populated by loss averse agents and normal agents with constant relative risk aversion. ${ }^{1}$ There is a single consumption good and other quantities (e.g. prices and dividends) are measured in units of this good. We assume that the agents trade one riskless bond and one risky stock continuously in a market without transaction costs. The bond is in zero net supply, while the stock is in constant net supply of 1 and pays out dividends at the rate $\delta(t)$, for $t \in[0, T]$. We assume that the dividend rate follows a Geometric Brownian motion:

$$
d \delta(t)=\mu_{\delta} \delta(t) d t+\sigma_{\delta} \delta(t) d B(t)
$$

with $\mu_{\delta}>0$ and $\sigma_{\delta}>0$ constants.

The equilibrium processes of the riskless money market account $S_{0}(t)$ and the stock price $S_{1}(t)$ are the following diffusions, as will be shown in Section 3:

$$
\begin{gathered}
d S_{0}(t)=r(t) S_{0}(t) d t, \\
d S_{1}(t)+\delta(t)=\mu(t) S_{1}(t) d t+\sigma(t) S_{1}(t) d B(t),
\end{gathered}
$$

where the interest rate $r(t)$, the drift rate $\mu(t)$ and the volatility $\sigma(t)$ are adapted processes (possibly path-dependent).

As the market is complete, these price processes imply the existence of a unique state price density (or pricing kernel) $\xi(t)$, given by

$$
\xi(t)=\exp \left(-\int_{0}^{t} r(s) d s\right) Z(t)
$$

where $Z(t)$ denotes the Radon-Nikodym derivative of a change of probability measure defined by

$$
Z(t)=\frac{d Q}{d P}=\exp \left(-\frac{1}{2} \int_{0}^{t} \kappa(s)^{2} d s-\int_{0}^{t} \kappa(s) d B(s)\right),
$$

and $\kappa(t)=(\mu(t)-r(t)) / \sigma(t)$ denotes the process for the market price of risk (Sharpe ratio).

Alternatively, we may write the state price density process as

$$
\frac{d \xi(t)}{\xi(t)}=-r(t) d t-\kappa(t) d B(t), \xi(0)=1
$$

\footnotetext{
${ }^{1}$ All stated processes are assumed to be well-defined and satisfy the appropriate regularity conditions. For technical details the reader is referred to Karatzas \& Shreve (1998).
} 
The pricing kernel $\xi(t)$ relates future dividend payments $\delta(s), s \in(t, T]$ to today's stock price $S_{1}(t)$ :

$$
S_{1}(t)=\frac{1}{\xi(t)} E_{t}\left[\int_{t}^{T} \xi(s) \delta(s) d s\right],
$$

The state price density process will therefore play an important role in deriving the equilibrium prices.

\subsection{Preferences, Consumption and Endowments}

The asset pricing literature traditionally focuses on rational and risk averse agents with constant relative risk aversion:

$$
V_{C R R A}(x)=\frac{1}{\gamma} x^{\gamma}, \text { for } \gamma<1 ; x>0
$$

where $x$ usually represents consumption or wealth. Note that the power utility function (7) is increasing and strictly concave and hence agents are assumed to be risk averse.

Over the past 30 years psychologists have found compelling evidence that people treat gains and losses differently, and in particular that losses loom larger than gains. This behavior was formalized by (Kahneman \& Tversky 1979) in a descriptive framework for decision-making under uncertainty, known as prospect theory. Recently, the behavioral aspects of decision-making have received a lot of attention in the financial literature. Benartzi \& Thaler (1995), Gomes (2000), and Barberis et al. (2000) try to explain the equity premium puzzle with loss aversion, while Odean (1998) focuses on the disposition effect. ${ }^{2}$

Prospect theory was originated by Kahneman \& Tversky (1979) who presented a number of choice problems to students and university faculty and found serious violations of expected utility theory. The main conclusions from these experiments are that people care about changes in wealth rather than the absolute value of wealth itself. Moreover, people care about small risks and they are risk seeking in the domain of losses. These findings are formalized in prospect theory: economic agents maximize an S-shaped value function that is concave for gains, convex for losses and steeper for losses than for gains:

$$
V_{L A}(x)= \begin{cases}-A(\theta-x)^{\gamma_{L}}, & \text { for } x \leq \theta \\ +B(x-\theta)^{\gamma_{G}}, & \text { for } x>\theta\end{cases}
$$

where $A>0$ and $B>0$ to ensure that $V_{L A}(\cdot)$ is an increasing function and $0<\gamma_{L} \leq 1$, $0<\gamma_{G} \leq 1$. An illustration of the value function can be found in Figure 1 .

Critical for the value function is the reference point $\theta$ distinguishing gains and losses. This reference point may represent the status quo of the investor (e.g. his current assets) or an aspiration level. Another reasonable reference point may be some liability: an investor concerned

\footnotetext{
${ }^{2}$ The disposition effect refers to the tendency of investors to sell winning investments too soon and hold losing investments too long, see e.g. Shefrin \& Statman (1985).
} 
with his balance sheet might only experience a loss as the value of his assets falls below the value of his liabilities. Odean (1998) uses the original purchase price of an asset as reference point. We interpret the reference point as an aspiration level throughout and assume that it is constant.

Another important finding of Kahneman \& Tversky (1979) is that individuals apply decision weights that over- or underweight the true probabilities. In order to study the investment problem under loss aversion we refrain from using subjective decision weights and assume that agents maximize expected values rather than prospective values. This assumption is also made by Barberis et al. (2000). Consequently, we model loss averse agents as expected utility maximizers with the utility function given by the value function (8) of Kahneman \& Tversky (1979).

We assume that a proportion $\lambda$ of the agents in the economy is normal and that the remaining proportion $(1-\lambda)$ is loss averse. Each normal agent is endowed at time zero with initial wealth $W_{1}(0)$, while each loss averse agent is endowed with $W_{2}(0)$. For both groups of agents we define a non-negative consumption process $c_{i}(t)$ and a process for the amount invested in stocks $\pi_{i}(t)$, for $i=1,2$. The wealth $W_{i}(t)$ of the agents then follows the process:

$$
\begin{aligned}
& d W_{i}(t)=r(t) W_{i}(t) d t+(\mu(t)-r(t)) \pi_{i}(t) d t-c_{i}(t) d t+\sigma(t) \pi_{i}(t) d B(t), \\
& \text { for } i=1,2 ; \forall t \in[0, T] .
\end{aligned}
$$

As in the case of asset prices, today's wealth can be related to future consumption and terminal wealth through the state price density process $\xi(t)$ :

$$
W_{i}(t)=\frac{1}{\xi(t)} E_{t}\left[\int_{t}^{T} \xi(s) c_{i}(s) d s+\xi(T) W_{i}(T)\right],
$$

The agents derive utility $U_{i}\left(c_{i}(t)\right)$ from intertemporal consumption in $[0, T]$ and utility $H_{i}\left(W_{i}(T)\right)$ from terminal wealth at the planning horizon $T$. The individual planning problem for each agent then is:

$$
\begin{array}{ll}
\max _{c_{i}, \pi_{i}} & E\left[\int_{0}^{T} U_{i}\left(c_{i}(s)\right) d s+\rho_{i} H_{i}\left(W_{i}(T)\right)\right] \\
\text { s.t. } & d W_{i}(t)=r(t) W_{i}(t) d t+(\mu(t)-r(t)) \pi_{i}(t) d t-c_{i}(t) d t+\sigma(t) \pi_{i}(t) d B(t), \\
& W_{i}(t) \geq 0, \text { for } i=1,2 ; \forall t \in[0, T] .
\end{array}
$$

where $\rho_{i}$ is a constant scaling parameter for $i=1,2$.

We assume that all agents have constant relative risk aversion over intertemporal consumption, $U_{i}\left(c_{i}(t)\right)=V_{C R R A}\left(c_{i}(t)\right)$ for $i=1,2$. The normal agents also have power utility over terminal wealth, $H_{1}\left(W_{1}(T)\right)=V_{C R R A}\left(W_{1}(T)\right)$, while the group of loss averse agents maximizes the value function over terminal wealth, $H_{2}\left(W_{2}(T)\right)=V_{L A}\left(W_{2}(T)\right)$. By assuming a common power utility function for intertemporal consumption, we can isolate the influence of loss aversion over terminal wealth on asset prices. The motivation for assuming loss aversion over terminal wealth only, and not over intermediate wealth, is that people evaluate their investment portfolio infrequently. The planning horizon $T$ can be interpreted as the first evaluation date for investment performance.

The evaluation frequency is a crucial notion in loss aversion. How often do investors evaluate their performance? As Benartzi \& Thaler (1995) point out people file taxes each year and many 
institutional investors are evaluated annually by regulating authorities. An evaluation period of one year seems very plausible. Even when saving for retirement a young investor may experience utility from gains and losses on his investments as he checks his investment account. Benartzi \& Thaler (1995) labeled the combination of loss aversion and a short evaluation period myopic loss aversion. Our main purpose is to study the effect of myopic loss aversion on the equilibrium stock price, the risk premium and volatility.

\subsection{Equilibrium Conditions and Optimal Decisions}

In equilibrium each agent maximizes his individual consumption-investment problem, while the markets for the riskless security and the stock have to clear at each time $t \in[0, T]$. Moreover, it follows from Walras law that aggregate consumption in the economy has to equal the aggregate dividends at each time $t \in[0, T]$. Combined, this gives the following set of equilibrium conditions:

$$
\begin{aligned}
\lambda c_{1}^{*}(t)+(1-\lambda) c_{2}^{*}(t) & =\delta(t), \\
\lambda \pi_{1}^{*}(t)+(1-\lambda) \pi_{2}^{*}(t) & =S_{1}(t), \\
\lambda W_{1}^{*}(t)+(1-\lambda) W_{2}^{*}(t) & =S_{1}(t),
\end{aligned}
$$

where $c_{i}^{*}(t)$ and $\pi_{i}^{*}(t)$ are the optimal consumption and investment decisions for each group of agents $i=1,2$ and $W_{i}^{*}(t)$ is the corresponding optimal wealth process.

The optimal policies for the group of normal agents with power utility can be derived with dynamic programming as in Merton (1969) and with the martingale methodology of Cox \& Huang (1989). For the loss averse agents the dynamic programming approach fails, as the value function of prospect theory is not differentiable in the reference point. Moreover, as the value function is also non-concave, the martingale methodology of Cox \& Huang (1989) can not be applied directly either. Berkelaar \& Kouwenberg (2000) extend the martingale methodology to allow for pseudo-concave utility functions and solve the consumption-investment problem of loss averse agents.

In the next proposition we characterize the optimal terminal wealth profile and consumption for both groups of agents:

Proposition 1 For any state price density following the process (5), the optimal intertemporal consumption policy $c_{i}^{*}(t)$ and terminal wealth profiles $W_{i}^{*}(T)$ of both groups of agents $i=1,2$ are

$$
\begin{aligned}
c_{1}^{*}(t) & =I_{1}\left(y_{1} \xi(t)\right)=\left(y_{1} \xi(t)\right)^{1 / \gamma-1}, \\
c_{2}^{*}(t) & =I_{2}\left(y_{2} \xi(t)\right)=\left(y_{2} \xi(t)\right)^{1 / \gamma-1}, \\
W_{1}^{*}(T) & =\left(y_{1} \xi(T)\right)^{1 / \gamma-1}, \\
W_{2}^{*}(T) & = \begin{cases}\theta+\left(\frac{y_{2} \xi(T)}{B \gamma_{G}}\right)^{1 /\left(\gamma_{G}-1\right)} & \text { for } \xi(T)<\bar{\xi} / y_{2} \\
0 & \text { for } \xi(T) \geq \bar{\xi} / y_{2},\end{cases}
\end{aligned}
$$

where $I_{i}(z)$ denotes the inverse of the marginal utility function over consumption $z=U_{i}^{\prime}(x)$, 
and $\bar{\xi}$ solves $f(\bar{\xi})=0$ with

$$
f(x)=\frac{1-\gamma_{G}}{\gamma_{G}}\left(\frac{1}{x}\right)^{\gamma_{G} /\left(1-\gamma_{G}\right)}\left(B \gamma_{G}\right)^{1 /\left(1-\gamma_{G}\right)}-\theta x+A \theta^{\gamma_{L}}
$$

and $y_{i} \geq 0$ are Lagrange multipliers, satisfying

$$
E\left[\int_{t}^{T} \xi(s) c_{i}^{*}(s) d s+\xi(T) W_{i}^{*}(T)\right]=\xi(0) W_{i}(0), \text { for } i=1,2 .
$$

In order to facilitate the derivation of equilibrium prices in the following sections, we additionally use the following proposition proved by Karatzas, Lehoczky \& Shreve (1990) and Basak (1995). It provides a different representation of the equilibrium conditions by applying the martingale methodology.

Proposition 2 If there exists a state price density process $\xi(t)$ satisfying

$$
\delta(t)=\lambda I_{1}\left(y_{1} \xi(t)\right)+(1-\lambda) I_{2}\left(y_{2} \xi(t)\right),
$$

where $y_{1}$ and $y_{2}$ are Lagrange multipliers defined in (15), then the equilibrium conditions (12) are satisfied by the corresponding optimal consumption and investment policies.

Before we actually derive the equilibrium prices, we will first discuss the optimal investment strategies of the agents. In Figure 2 we display the optimal terminal wealth profile for both loss averse agents and normal agents. All agents have initial wealth $W_{i}(0)=1$ and power utility over consumption with risk aversion $\gamma=-1$. The normal agents also have a power utility function over terminal wealth with $\gamma=-1$ and no scaling $\left(\rho_{1}=1\right)$. For the value function of the loss averse agents we apply the parameter values estimated by Kahneman \& Tversky (1979) $\left(\gamma_{L}=\gamma_{G}=0.88, A=2.25, B=1.0\right)$, scaling factor $\rho_{2}=10$ and a threshold equal to initial wealth, $\theta=W(0)$.

Figure 2 shows that the optimal terminal wealth function of the normal agents is decreasing smoothly from good states of the world (low $\xi(T)$ ) to bad states (high $\xi(T)$ ). The loss averse agents behave quite differently: in the good state region (low $\xi(T)$ ) they require much more terminal wealth than the normal agents, due to low risk aversion over gains. Their optimal wealth function is also relatively steep in good states. In average and bad states up to $\bar{\xi} / y_{2}$, the loss averse agents try to keep their wealth above the threshold $\theta$ and as a result the wealth function becomes quite flat. In very bad states, from $\bar{\xi} / y_{2}$ onwards, this strategy is no longer feasible and terminal wealth suddenly drops to zero.

Berkelaar \& Kouwenberg (2000) demonstrate that the optimal investment strategy of loss averse agents can be considered as a combination of a growth strategy and a binary option. The growth strategy produces the steep increase of terminal wealth in good states of the world. In average and bad states the loss averse agents try to maximize the probability that their wealth stays above the threshold $\theta$ and for that purpose they hold a binary option. This binary option pays off $\theta$ if the state of the world $\xi(T)$ is better than $\bar{\xi} / y_{2}$ and nothing otherwise. Finally, in states worse than $\bar{\xi} / y_{2}$ the loss averse agents end up with zero wealth. 
Figure 3 displays the optimal fraction invested in stocks as a function of wealth $W(t)$ for both groups of agents, at an intermediate point in time $t<T .^{3}$ The normal investors dedicate a constant fraction of wealth to stocks. For the loss averse agents the portfolio weight of stocks is minimal in the neighborhood of the threshold $\theta$, while it increases sharply at both high and low levels of wealth. At high levels of wealth this policy is driven by low risk aversion over gains, while at low levels of wealth the probability maximizing strategy (i.e. the binary option) results in an increasing stock fraction.

We conclude that loss averse investors follow a momentum strategy (buy high, sell low) at high levels of wealth relative to their threshold, around the threshold they become more risk averse, while they switch to a contrarian strategy (buy low, sell high) if wealth drops considerably below the threshold. In the following sections we will investigate the impact of this investment behavior on equilibrium prices.

\section{$3 \quad$ Equilibrium with Loss Averse Agents}

In this section we derive closed-form solutions for the equilibrium prices in an economy where a fraction $\lambda$ of the agents is normal and the remaining fraction $1-\lambda$ is loss averse. As a first step, it is convenient to derive the equilibrium state price density as a function of aggregate dividends by inverting equation (16). Given the stochastic process for the state price density in (5), as a second step we can infer the equilibrium interest rate and market price of risk. The following proposition summarizes these general results:

Proposition 3 In any economy with $0 \leq \lambda \leq 1$ equilibrium exists and the state price density is given by

$$
\xi(t)=\left(v\left(y_{1}, y_{2}\right) \delta(t)\right)^{\gamma-1},
$$

where

$$
v\left(y_{1}, y_{2}\right)=\left(\lambda y_{1}^{1 / \gamma-1}+(1-\lambda) y_{2}^{1 / \gamma-1}\right)^{-1} .
$$

The equilibrium interest rate and market price of risk processes are constant:

$$
\begin{aligned}
& r(t)=(1-\gamma)\left(\mu_{\delta}+1 / 2(\gamma-2) \sigma_{\delta}^{2}\right) \\
& \kappa(t)=(1-\gamma) \sigma_{\delta} .
\end{aligned}
$$

An important conclusion from Proposition 3 is that the interest rate $r$ and the market price of risk $k$ are constant in equilibrium. Moreover, the fraction of loss averse agents in the economy does not affect the interest rate and the market price of risk. Hence, in our setup the presence of loss averse agents will only have impact on the price level of the stock, on its drift rate $\mu$ and

\footnotetext{
${ }^{3}$ In order to derive the optimal investment strategy as a function of wealth (instead of the pricing kernel $\xi$ ), we assume that the riskless rate $r$ is constant and the stock follows a geometric Brownian motion with constant mean and volatility. See Berkelaar \& Kouwenberg (2000).
} 
volatility $\sigma$. Note however, that the mean and volatility always have to move in lockstep due to the constant market price of risk.

The constant interest rate and market price of risk arise due to the assumption that both groups of agents share an identical power utility function over intertemporal consumption. Although this economic setup leads to some inflexibility, a major advantage is that we can derive closedform solutions for the prices and hence fully analyze the economic problem at hand. Basak (1995) and Basak \& Shapiro (1999) impose equivalent assumptions in order to study equilibrium with portfolio insurers and value-at-risk regulation respectively. Without an identical utility function over consumption for both groups of agents, we would have to resort to numerical techniques as in Grossman \& Zhou (1996). ${ }^{4}$

Given the state price density of Proposition 3, we can derive the equilibrium stock price from the equilibrium conditions (12). Once a closed-form expression has been obtained, the drift rate $\mu$ and volatility $\sigma$ of the stock price process follow straightforwardly from Ito's lemma. Below we first present the equilibrium price in a benchmark economy with normal investors only $(\lambda=1)$, before we consider our general results with loss averse agents:

Proposition 4 The equilibrium price of the risky asset in an economy with normal agents only $(\lambda=1)$ is

$$
S_{1}(t)=\delta(t)\left(a(t)+e^{\eta(T-t)}\right)
$$

with

$$
a(t)=\frac{1}{\eta}\left(e^{\eta(T-t)}-1\right), \quad \eta=\gamma \mu_{\delta}-1 / 2 \gamma(1-\gamma) \sigma_{\delta}^{2}
$$

The stock price follows a geometric Brownian motion with constant drift rate and volatility given by

$$
\mu(t)=(1-\gamma)\left(\mu_{\delta}+1 / 2 \gamma \sigma_{\delta}^{2}\right), \quad \sigma(t)=\sigma_{\delta}
$$

In the case of normal agents with power utility the interest rate is constant and the stock price follows a Geometric Brownian motion, resembling the familiar Black-Scholes assumptions for option pricing. If we additionally introduce loss averse agents $(\lambda<1)$, then the equilibrium stock price process changes quite drastically:

Proposition 5 The equilibrium price of the risky asset in an economy with both normal and loss averse agents is

$$
\begin{aligned}
S_{1}(t)= & a(t) \delta(t)+\lambda y_{1}^{1 / \gamma-1} v\left(y_{1}, y_{2}\right) e^{\eta(T-t)} \delta(t)+ \\
& (1-\lambda)\left(\theta e^{-r(T-t)} N\left(d_{2}(\delta, t)\right)+\left(\frac{B \gamma_{G}}{y_{2}}\right)^{1 / 1-\gamma_{G}} e^{\Gamma(t)}\left(v\left(y_{1}, y_{2}\right) \delta(t)\right)^{\frac{1-\gamma}{1-\gamma_{G}}} N\left(f_{2}(\delta, t)\right)\right)
\end{aligned}
$$

\footnotetext{
${ }^{4}$ The same holds if we would leave out consumption and only assume utility over terminal wealth.
} 
with

$$
\begin{aligned}
d_{i}(\delta, t) & =\frac{\log \left(\bar{\xi}_{i} / y_{i}\right)+(1-\gamma)\left(\log (\delta(t))+\log \left(v\left(y_{1}, y_{2}\right)\right)\right)+\left(r-\frac{1}{2} \kappa^{2}\right)(T-t)}{\kappa \sqrt{(T-t)}}, \\
f_{i}(\delta, t) & =d_{i}(\delta, t)+\frac{\kappa \sqrt{(T-t)}}{1-\gamma_{G}}, \text { for } i=1,2 \\
\Gamma(t) & =\frac{\gamma_{G}}{1-\gamma_{G}}\left(r+\frac{1}{2} \kappa^{2}\right)(T-t)+\frac{1}{2}\left(\frac{\gamma_{G}}{1-\gamma_{G}}\right)^{2} \kappa^{2}(T-t),
\end{aligned}
$$

where $\bar{\xi}_{i}$ solves equation (14). ${ }^{5}$

In an economy with loss averse investors the drift rate and volatility of the stock price process are no longer constant, which can be easily verified by applying Ito's lemma to the stock price formula (23). Given these closed-form solutions, we will now analyze the impact of loss aversion on the equilibrium stock price, its drift rate and volatility. It will turn out later that these quantities can be both higher and lower in the presence of loss averse agents (relative to benchmark economy), depending on the particular state of the world. Hence, we can not conclude much analytically about the sign of these changes and numerical investigations are therefore required.

For our numerical examples we set the parameters of the dividend process as $\mu_{\delta}=0.056$ and $\sigma_{\delta}=0.115$, based on monthly S\&P500 index data from 1980 up to 1999. All agents have initial wealth $W_{i}(0)=1$ and power utility over consumption with risk aversion $\gamma=-1$. The normal agents also have power utility over terminal wealth with $\gamma=-1$ and no scaling $\left(\rho_{1}=1\right)$. For the loss averse agents we take the parameter values estimated by Kahneman \& Tversky (1979) for the value function, scaling factor $\rho_{2}=10$ and threshold $\theta=1$.

Figure 4 shows the equilibrium price of the risky asset in the benchmark economy $(\lambda=1)$ and in a mixed economy with $50 \%$ loss averse agents $(\lambda=1 / 2)$, at the intermediate time $t=1 / 2$. The price in the benchmark economy is smoothly decreasing from good states of the world (low $\xi(t))$ to bad states (high $\xi(t)$ ). However, if loss averse agents enter the market then the price function changes sharply. In good states of the world there is a remarkable explosion of prices. In intermediate states the price remains quite stable on a relatively high level. Finally, in bad states the stock price drops rapidly below the level of the benchmark economy.

The price function in the presence of loss averse agents can be explained quite well by studying the optimal investment strategy. As pointed out in the previous section, loss averse investors are quite tolerant to risk if their wealth exceeds the benchmark level. Hence, in good states of the world the stock price rises sharply due to the demand pressure of the loss averse agents. This explains the strong boom of the stock price in the left hand side of Figure 4. Figure 5 and 6 demonstrate that the drift rate and volatility of the stock return also jump up simultaneously, due to the decreasing level of risk aversion in the economy.

\footnotetext{
${ }^{5}$ Note that $d_{1}(\delta, t), f_{1}(\delta, t)$ and $\bar{\xi}_{1}$ are only defined and used in economies with heterogeneous loss averse agents, see Section 4 .
} 
In bad states with low wealth the loss averse agents switch to a probability maximizing strategy, aiming to keep wealth above the target. This strategy (replicating the payoff of a binary option) prescribes an increasing portfolio weight of stocks as wealth decreases. Hence, in bad states the loss averse agents follow a contrarian strategy and their demand supports the relatively high price level compared to the benchmark economy. The mean and volatility of the stock returns are relatively low in this intermediate region, as shown in Figure 5 and 6.

In extremely bad states of the world, the probability maximizing strategy is no longer feasible, as it involves an increasing portfolio weight of stocks. At some point the loss averse agents will start to diminish their stock position in order to meet margin calls and to avoid bankruptcy. While this forced retreat from the stock market takes place, the stock price drops down quite rapidly while both the mean and the volatility of the stock return rise. The increase of the mean return in very bad states might seem puzzling at first sight, but is required to lure the normal agents into buying stocks of the distressed loss averse agents.

Concluding, we observe that the presence of loss averse agents has a remarkable impact on the equilibrium stock price. The price function displays a volatile journey from boom til bust, with a relatively stable price regime in between. For other parameter values we find qualitatively similar results, as in all cases the price movements relative to the benchmark economy are driven by the optimal investment strategy of the loss averse agents. For example, Figure 7 shows the equilibrium price at time $t=0.75$ instead of $t=0.5$. The price functions in Figures 4 and 7 have a similar shape.

Finally, we take a closer look at the stock price process by calculating the expected drift rate $\mu$ as a function of the price level $S_{1}(t)$ at time $t=0.5$. Figure 8 shows that the expected stock return in the economy with loss averse agents goes up as the price level increases above its initial value $S_{1}(0)=1$. Hence, in good states of the world (high $S_{t}(t)$ ) the returns are mean-averting due to the momentum strategy followed by the loss averse investors. In intermediate states, there is a small region where the expected return is lower than in the benchmark economy. Here the loss averse investors stabilize prices with their contrarian strategy, while replicating the binary option.

If the price drops further the expected return starts to increase again. This increase is due to the gradual retreat of the loss averse agents from the market, selling their stocks to the normal agents at a discount. Once the loss averse agents are out of the market, the expected return goes back to the benchmark level. We conclude that stock returns in our economy with loss averse agents display mean-aversion when prices are high and mean-reversion when prices are (moderately) low. At first sight, this might seem a perfect deal for investors: low prices tend to bounce up, while high prices tend to rise further. However, volatility also rises considerably in both cases. 
From Boom til Bust: How Loss Aversion Affects Asset Prices

\section{Equilibrium with Heterogeneous Loss Averse Agents}

In the previous section we considered an economy with two homogeneous groups of agents, normal and loss averse. Clearly, in practice investors also differ from each other in a number of other aspects. For example, people have different initial wealth and this will affect their investment decisions. For power utility though, it is a well-know fact that the distribution of initial wealth does not affect equilibrium prices. Rubinstein (1974) and Constantinides (1982) prove that a group of heterogeneous power-agents having different initial wealth but equal risk aversion $\gamma$, can be represented equivalently by one aggregate power-investor.

However, in the case of loss averse agents with different initial wealth this result might no longer hold. The obvious reason is that it matters a lot for a loss averse investor whether his wealth is above the threshold or below. As we have discussed previously, loss averse investors with wealth above the threshold pursue a growth strategy, while below the threshold they maximize the probability of getting even. A similar argument holds if we would consider two loss averse agents with different thresholds. This makes it very unlikely that an economy with heterogeneous loss averse investors can be represented by an equivalent economy with one aggregate loss averse agent.

In order to investigate this aggregation issue, we study an economy with two groups of loss averse agents, who are identical except for their threshold and initial wealth. A fraction $\varphi$ of the loss averse agents has initial wealth $W_{1}(0)$ and threshold $\theta_{1}$, while the remaining fraction $(1-\varphi)$ has initial wealth $W_{2}(0)$ and threshold $\theta_{2}$. As before, we let $y_{i}$ denote the Lagrange multipliers of the budget equation for both groups $i=1,2$. The following proposition provides a closed-form expression for the equilibrium stock price in the economy:

Proposition 6 The equilibrium price of the risky asset in an economy with two groups of loss averse agents with different threshold $\theta_{i}$ and initial wealth $W_{i}(0)$, for $i=1,2$, is

$$
\begin{aligned}
S_{1}(t)= & a(t) \delta(t)+ \\
& \varphi\left(\theta_{1} e^{-r(T-t)} N\left(d_{1}(\delta, t)\right)+\left(\frac{B \gamma_{G}}{y_{1}}\right)^{1 / 1-\gamma_{G}} e^{\Gamma(t)}\left(v\left(y_{1}, y_{2}\right) \delta(t)\right)^{\frac{1-\gamma}{1-\gamma_{G}}} N\left(f_{1}(\delta, t)\right)\right)+ \\
& (1-\varphi)\left(\theta_{2} e^{-r(T-t)} N\left(d_{2}(\delta, t)\right)+\left(\frac{B \gamma_{G}}{y_{2}}\right)^{1 / 1-\gamma_{G}} e^{\Gamma(t)}\left(v\left(y_{1}, y_{2}\right) \delta(t)\right)^{\frac{1-\gamma}{1-\gamma_{G}}} N\left(f_{2}(\delta, t)\right)\right)
\end{aligned}
$$

with $a(t)$ given by (21), $d_{i}(\delta, t), f_{i}(\delta, t)$ and $\Gamma(t)$ given by (24) and $\bar{\xi}_{i}$ as defined in (14). Note that $\bar{\xi}_{1}$ and $\bar{\xi}_{2}$ are not equal in this case, due to the different thresholds $\theta_{1}$ and $\theta_{2}$.

Figure 9 shows the equilibrium stock price at time $t=0.75$ in an economy with loss averse agents only, where a proportion $\varphi=0.5$ of the agents has initial wealth $W_{1}(0)=0.75$ and the other group of agents has initial wealth $W_{2}(0)=1.25$. As a benchmark we also show the equilibrium price in an economy with one loss averse investor, having initial wealth 1 . The remaining coefficients and parameters are the same as in the previous section.

It is clear from Figure 9 that the price function in an economy with heterogeneous agents differs from the benchmark case. In the heterogeneous economy the price level is higher in good states, 
due to the excess demand of the wealthy individuals $\left(W_{2}(0)=1.25\right)$. This higher price level can no longer be supported when the poor agents $\left(W_{1}(0)=0.75\right)$ run out of funds, and hence in moderately bad states the stock price drops below the benchmark level. In very bad states, the agents of the benchmark economy also have to leave the market while the rich individuals in the heterogeneous economy still survive. Consequently, the equilibrium price is above the benchmark level again at the right end of the graph.

Figure 10 displays the volatility of the stock return in the two economies. In general, loss averse agents increase volatility when they are above their threshold (while following a momentum strategy) and when they leave the market in very bad states. Hence, in the heterogeneous economy the volatility is relatively high in good states, as the rich individuals drive up prices with their momentum trading. In moderately bad states the volatility in the heterogeneous economy is also higher, due to the gradual bankruptcy problems of the poor individuals. Then in very bad states, turmoil in the benchmark economy is relatively high as agents leave the market, while the rich individuals in the heterogeneous case are still alive.

The behavior of the drift rate is similar to the volatility of the stock return, due the constant market price of risk. We also considered a heterogeneous economy where the two groups of loss averse agents have equal initial wealth $\left(W_{1}(0)=W_{2}(0)=1\right)$, but different thresholds $\theta_{1}=1.25$ and $\theta_{2}=0.75$. As can be seen in Figure 11, the price function in this case is qualitatively similar to the case with different initial wealth. We conclude that the aggregation of heterogeneous loss averse agents with differences in initial wealth or threshold is not possible. In general, heterogeneity will tend to smooth abrupt changes of the stock price and its volatility. However, the absolute level of the stock price and its volatility might rise, as the behavior of some individuals is more extreme (e.g. very wealthy investors).

\section{A Note on the Equity Premium Puzzle}

One of the most striking puzzles in finance, is the question why, historically, the average return on equity has been so much higher than interest rates. This fact was first observed by Mehra \& Prescott (1985). The puzzling element is why we cannot explain this with classical economic models assuming rationality, risk aversion, and markets without frictions. Over the last decade a stream of literature has attempted to explain this so-called equity premium puzzle. Possible explanations include market imperfections (Basak \& Cuoco 1998), incompleteness (Constantinides $\&$ Duffie 1996), and alternative assumptions on preferences such as habit formation (Campbell \& Cochrane 1999) and loss aversion (Barberis et al. 2000).

Let us demonstrate the equity premium puzzle with some figures. Previously, we used dividend data in our numerical experiments. However, the clearing conditions (12) state that aggregate consumption should equal dividends. What are the equity premium and volatility of stock returns in an equilibrium with normal agents if we use empirical data on US consumption? Using the US annual consumption data from Barberis et al. (2000) over the period 1889 to 1985, we observe that the average growth rate equals $\mu_{c}=1.84 \%$ with standard deviation $\sigma_{c}=3.79 \%$. 
Recall that the equity premium in the benchmark economy is given by $\mu-r=(1-\gamma) \sigma_{c}^{2}$ and the volatility of stock returns is $\sigma=\sigma_{c}$ (see Proposition 3). Assuming a risk aversion coefficient of $\gamma=-1$, we obtain an equity premium of $\mu-r=0.3 \%$ and a volatility of $3.79 \%$, if we use consumption data. These figures demonstrate clearly that the equity premium and the volatility of stock returns do not even come close to historically observed figures in a model based on consumption data, power utility and a frictionless market. We could increase the equity premium by assuming higher risk aversion, however the volatility remains the same.

The difficulty in explaining the equity premium puzzle with traditional models mainly stems from the fact that the volatility of consumption growth is extremely small compared to the volatility of stock returns. ${ }^{6}$ Recently, Campbell \& Cochrane (1999) and Barberis et al. (2000) have demonstrated that preferences with time-varying risk aversion can increase volatility. Campbell \& Cochrane (1999) focus on consumption habits, whereas Barberis et al. (2000) consider a combination of prospect theory and the house money effect of Thaler \& Johnson (1990) to resolve the equity premium puzzle. In both models time-varying risk aversion generates timevarying risk premia, resulting in more volatile asset prices than the underlying dividends (and consumption).

Barberis et al. (2000) consider an infinite horizon discrete-time model with intertemporal power utility over consumption and loss averse preferences over wealth. The aggregate loss averse investor evaluates his gains and losses at the end of each discrete-time period. As the model of Barberis et al. (2000) includes multiple evaluation dates, the loss averse investors have to update their benchmark level. Barberis et al. (2000) assume that the loss averse investor slowly adjusts the threshold to realized gains and losses, not immediately. Additionally, Barberis et al. (2000) assume that risk aversion decreases after gains and increases after losses. ${ }^{7}$ With this particular model Barberis et al. (2000) explain a considerable share of the equity premium puzzle.

In this paper we analyze the micro-economic effects of loss aversion on asset prices in a model with a finite horizon, over the course of one evaluation period of the loss averse investors. Moreover, we allow for continuous trading up to the evaluation date. Hence, our approach and aim are quite different from Barberis et al. (2000). It is still an interesting question though, whether we can explain and confirm the results reported by Barberis et al. (2000), as we have closed form solutions while Barberis et al. (2000) rely on simulations to calculate the equilibrium prices. Moreover, Barberis et al. (2000) assume that the value function is piecewise linear (ignoring risk aversion over gains) and that there is one representative loss averse agent.

For illustrative purposes we also consider an economy with one representative loss averse agent, in order to compare the results with Barberis et al. (2000). Figure 12 shows the equity premium at $t=0$ as a function of the threshold $\theta$, given risk aversion $\gamma=0$, scaling factor $\rho=100$ and initial wealth $W(0)=1$. We observe that the equity premium increases, if the initial wealth of the loss averse investor is larger than the threshold (i.e. $\theta<W(0)=1$ ). Effectively, this situation represents an investor who has enjoyed prior gains. Similarly, as he suffered prior losses

\footnotetext{
${ }^{6}$ Even when relying on dividends, the volatility of stock returns $\sigma=\sigma_{\delta}=11.5 \%$ does not come close to the empirically observed volatility of $20 \%$.

${ }^{7}$ This is achieved by making the parameters $A$ and $B$ of the value function (8) depend on the time-varying benchmark level.
} 
(i.e. $\theta>W(0)=1$ ), the equity premium also increases. Figure 13 shows the volatility at $t=0$ as a function of the threshold, which is similar due to the constant Sharpe ratio.

We may conclude that our model is able to generate a relatively high equity premium and volatility if investors are far from their benchmark, both initially and intertemporally. These results reinforce the conclusions of Barberis et al. (2000) on the effect of prior outcomes on the mean and volatility of stock returns. Barberis et al. (2000) assume that the loss averse investor adjusts his threshold each period according to a sluggish updating rule As wealth will tend to rise above the benchmark on average, this may be compared with our results when initial wealth exceeds the threshold. Consider Figure 12 and 13: we observe that equity premium and volatility increase as the wealth of the investor exceeds the threshold. Similar results hold for the equity premium.

\section{Conclusions}

In this paper we studied the impact of loss aversion on asset prices. We derived closed-form solutions for the market price (and mean and volatility) in an economy with heterogeneous agents. Some agents are normal whereas other agents are loss averse. In good states of the world, the loss averse investors with wealth above the threshold are momentum traders, thereby pushing prices far above the level in the benchmark economy. In moderately bad states of the world, the loss averse investors are contrarian, and equilibrium prices are kept relatively high and stable. Finally in extremely bad states, the loss averse investors are forced to retreat from the stock market in order to avoid bankruptcy, resulting in a sharp price drop.

Our findings can be summarized as follows:

1. The riskfree rate and the market price of risk (or Sharpe ratio) are constant, as we assume that both the normal and the loss averse agents have a power utility function over consumption.

2. In good states of the world the presence of loss averse investors with wealth above the threshold stimulates a boom in stock prices, while in extremely bad states the presence of loss averse investors results in a sharp drop in prices. At intermediate and moderately bad states, the presence of loss averse investors stabilizes prices at a relatively high level.

3. In general, the presence of loss averse investors increases both the mean return on stocks and the volatility.

4. Asset returns are predictable. When prices are high, stock returns are mean-averting. When prices are (moderately) low, stocks returns are mean-reverting.

5. Volatility is non-constant. In good states of the world an increase in prices raises the volatility. In bad states of the world an increase in prices decreases the volatility.

We believe that our equilibrium analysis may shed light on the recent surge of major stock markets in the world (during the late 1990s). The "irrational exuberance" that Alan Greenspan 
mentioned in 1996 might well be due to the presence of loss averse agents. Loss aversion may result in "unduly escalated" stock prices and increasing volatility, due to decreasing risk aversion. Moreover, our results demonstrate how loss aversion leads to a time-varying level of risk aversion, as the wealth of loss averse investors moves relative to their threshold. We also confirm the conclusions of Barberis et al. (2000) regarding loss aversion and the equity premium puzzle.

In our model with one evaluation period, we demonstrate that the ratio of wealth to the benchmark (threshold) of loss averse investors has a strong impact on the stock price, the mean return and the volatility. Consequently, an important issue is how people update their benchmark dynamically through time, from one evaluation date to the other. Barberis et al. (2000) choose a sluggish updating rule, motivated by their effort to fit the equity premium with consumption data. An interesting question for future research is how people actually update their benchmark in practice, as the original description of prospect theory of Kahneman \& Tversky (1979) only applies to one-shot gambles.

\section{References}

Barberis, N., Huang, M. \& Santos, T. (2000), Prospect theory and asset prices, forthcoming in Quarterly Journal of Economics, University of Chicago.

Basak, S. (1995), 'A general equilibrium model of portfolio insurance', Review of Financial Studies 8(4), 1059-1090.

Basak, S. \& Cuoco, D. (1998), 'An equilibrium model with restricted stock market participation', Review of Financial Studies 11, 309-341.

Basak, S. \& Shapiro, A. (1999), Value-at-risk based risk management: Optimal policies and asset prices, Working paper, The Wharton School, University of Pennsylvania.

Benartzi, S. \& Thaler, R. (1995), 'Myopic loss aversion and the equity premium puzzle', Quarterly Journal of Economics 110(1), 73-92.

Berkelaar, A. \& Kouwenberg, R. (2000), Optimal portfolio choice under loss aversion, Working paper, Econometric Institute Report EI2000-08/A, Erasmus University Rotterdam, The Netherlands.

Campbell, J. Y. \& Cochrane, J. H. (1999), 'By force of habit: A consumption-based explanation of aggregate stock market behavior', Journal of Political Economy 107, 205-251.

Constantinides, G. (1982), 'Intertemporal asset pricing with heterogeneous consumers and without demand aggregation', Journal of Business 55(2), 253-267.

Constantinides, G. \& Duffie, D. (1996), 'Asset pricing with heterogeneous consumers', Journal of Political Economy 104, 219-240.

Cox, J. \& Huang, C. (1989), 'Optimum consumption and portfolio policies when asset prices follow a diffusion process', Journal of Economic Theory 49, 33-83.

Gomes, F. (2000), Loss aversion and the demand for risky assets, Working paper, Harvard University.

Grossman, S. \& Zhou, Z. (1996), 'Equilibrium analysis of portfolio insurance', Journal of Finance 51(4), 1379-1403. 
Kahneman, D. \& Tversky, A. (1979), 'Prospect theory: An analysis of decision under risk', Econometrica 47, 263-290.

Karatzas, I., Lehoczky, J. \& Shreve, S. (1987), 'Optimal portfolio and consumption decisions for a 'small investor' on a finite horizon', SIAM Journal on Control and Optimization 25, $1157-1186$.

Karatzas, I., Lehoczky, J. \& Shreve, S. (1990), 'Existence and uniqueness of multi-agent equilibrium in a stochastic, dynamic consumption/investment model', Mathematics of Operations Research 15, 80-128.

Karatzas, I. \& Shreve, S. (1998), Methods of Mathematical Finance, Springer Verlag.

Lucas, R. (1978), 'Asset prices in an exchange economy', Econometrica 46, 1429-1445.

Mehra, R. \& Prescott, E. (1985), 'The equity premium: A puzzle', Journal of Monetary Economics pp. 145-161.

Merton, R. (1969), 'Lifetime portfolio selection under uncertainty: The continuous-time case', Review of Economics and Statistics 51, 247-257.

Odean, T. (1998), 'Are investors reluctant to realize their losses?', Journal of Finance 53, 17751798.

Rubinstein, M. (1974), 'An aggregation theorem for securities markets', Journal of Financial Economics 1, 255-244.

Shefrin, H. \& Statman, M. (1985), 'The disposition to sell winners too early and ride losers too long: Theory and evidence', Journal of Finance 40(3), 777-790.

Thaler, R. \& Johnson, E. (1990), 'Gambling with the house money and trying to break even: The effects of prior outcomes on risky choice', Management Science 36, 643-661. 


\section{A Appendix}

Proof of Proposition 1 We refer to Cox \& Huang (1989) and Karatzas, Lehoczky \& Shreve (1987) for the optimal consumption and investment policies for agents with power utility. Berkelaar \& Kouwenberg (2000) derive the optimal policies for loss averse agents.

Proof of Proposition 2 This proof can be found in Karatzas et al. (1990) and Basak (1995).

Proof of Proposition 3 If we substitute the optimal consumption policies (13) into equilibrium relationship (16), then we find:

$$
\delta(t)=\lambda\left(y_{1} \xi(t)\right)^{1 / \gamma-1}+(1-\lambda)\left(y_{2} \xi(t)\right)^{1 / \gamma-1}=\left(\lambda y_{1}^{1 / \gamma-1}+(1-\lambda) y_{2}^{1 / \gamma-1}\right) \xi(t)^{1 / \gamma-1},
$$

and hence the state price density in equilibrium is

$$
\xi(t)=\left(\lambda y_{1}^{1 / \gamma-1}+(1-\lambda) y_{2}^{1 / \gamma-1}\right)^{1-\gamma} \delta(t)^{\gamma-1}=\left(v\left(y_{1}, y_{2}\right) \delta(t)\right)^{\gamma-1}
$$

By applying Ito's lemma, we can derive that $\xi(t)$ follows the stochastic process below:

$$
\begin{aligned}
& d \xi(t)=\left((\gamma-1) \mu_{\delta}+1 / 2(\gamma-1)(\gamma-2) \sigma_{\delta}^{2}\right)\left(v\left(y_{1}, y_{2}\right) \delta(t)\right)^{\gamma-1} d t+ \\
&(\gamma-1) \sigma_{\delta}\left(v\left(y_{1}, y_{2}\right) \delta(t)\right)^{\gamma-1} d B(t) \\
&=\left((\gamma-1) \mu_{\delta}+1 / 2(\gamma-1)(\gamma-2) \sigma_{\delta}^{2}\right) \xi(t) d t+(\gamma-1) \sigma_{\delta} \xi(t) d B(t) .
\end{aligned}
$$

Equating the processes (5) and (28), we can determine the constant interest rate $r$ and the constant market price of risk $\kappa$.

Proof of Proposition 4 The equilibrium stock price in an economy with normal agents is a special case of Proposition 5 with $\lambda=1$ (see proof below). The drift rate $\mu(t)$ and volatility $\sigma(t)$ of the process can be derived by applying Ito's lemma to the stock price.

Proof of Proposition 5 The price of the risky asset can be derived from the third equilibrium condition in (12):

$$
S_{1}(t)=\lambda W_{1}^{*}(t)+(1-\lambda) W_{2}^{*}(t)
$$


Given the optimal policies of a normal agent and the process for $\delta(t)$, we can derive:

$$
\begin{aligned}
W_{1}^{*}(t) & =\frac{1}{\xi(t)} E_{t}\left[\int_{t}^{T} \xi(s) c_{1}^{*}(s) d s+\xi(T) W_{1}^{*}(T)\right] \\
& =\frac{1}{\xi(t)}\left(E_{t}\left[\int_{t}^{T} \xi(s)\left(y_{1} \xi(s)\right)^{1 / \gamma-1} d s\right]+E_{t}\left[\xi(T)\left(y_{1} \xi(T)\right)^{1 / \gamma-1}\right]\right) \\
& =\frac{1}{\xi(t)} y_{1}^{1 / \gamma-1} v\left(y_{1}, y_{2}\right)^{\gamma}\left(E_{t}\left[\int_{t}^{T} \delta(t)^{\gamma} d s\right]+E_{t}\left[\delta(T)^{\gamma}\right]\right) \\
& =y_{1}^{1 / \gamma-1} v\left(y_{1}, y_{2}\right) \delta(t)^{1-\gamma}\left(a(t) \delta(t)^{\gamma}+e^{\eta(T-t)} \delta(t)^{\gamma}\right) \\
& =y_{1}^{1 / \gamma-1} v\left(y_{1}, y_{2}\right)\left(a(t)+e^{\eta(T-t)}\right) \delta(t) .
\end{aligned}
$$

Similarly, we find for the loss averse agents:

$$
\begin{aligned}
W_{2}^{*}(t)= & \frac{1}{\xi(t)} E_{t}\left[\int_{t}^{T} \xi(s) c_{2}^{*}(s) d s+\xi(T) W_{2}^{*}(T)\right] \\
= & y_{2}^{1 / \gamma-1} v\left(y_{1}, y_{2}\right) a(t) \delta(t)+\frac{1}{\xi(t)} E_{t}\left[\xi(T) W_{2}^{*}(T)\right] \\
= & y_{2}^{1 / \gamma-1} v\left(y_{1}, y_{2}\right) a(t) \delta(t)+\frac{1}{\xi(t)} E_{t}\left[\xi(T)\left(\theta+\left(\frac{y_{2} \xi(T)}{B \gamma_{G}}\right)^{1 /\left(\gamma_{G}-1\right)}\right) \mathbf{1}_{\left\{\xi(T) \leq \bar{\xi} / y_{2}\right\}}\right] \\
= & y_{2}^{1 / \gamma-1} v\left(y_{1}, y_{2}\right) a(t) \delta(t)+\theta e^{-r(T-t)} N\left(d_{2}(\delta, t)\right)+ \\
& \left(\frac{B \gamma_{G}}{y_{2}}\right)^{1 / 1-\gamma_{G}} e^{\Gamma(t)}\left(v\left(y_{1}, y_{2}\right) \delta(t)\right)^{\frac{1-\gamma}{1-\gamma_{G}}} N\left(f_{2}(\delta, t)\right)
\end{aligned}
$$

where $\mathbf{1}_{\left\{\xi(T) \leq \bar{\xi} / y_{2}\right\}}$ denotes the indicator-function. Finally, by substituting (30) and (31) into (29) we get the equilibrium price.

Proof of Proposition 6 Equivalent to the proof of Proposition 5, except that both groups of agents are loss averse with different initial wealth (and hence different Lagrange multipliers $y_{i}$ ) and different threshold $\theta_{i}$ (and hence different parameters $\bar{\xi}_{i}$ ) for $i=1,2$. 
Figure 1: Value Function of a Loss Averse Agent

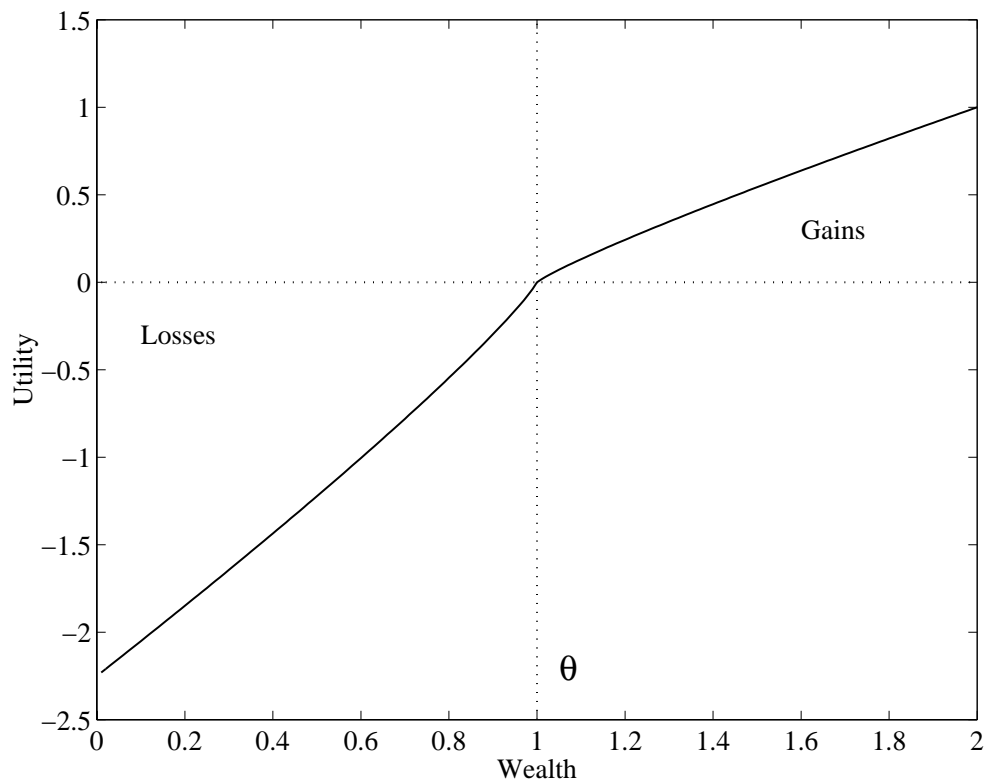

This figure shows the value function of a loss averse agent. The parameters used are $\gamma_{L}=\gamma_{G}=0.88$, $A=2.25, B=1.0$, and $\theta=1.0$.

Figure 2: Optimal Terminal Wealth

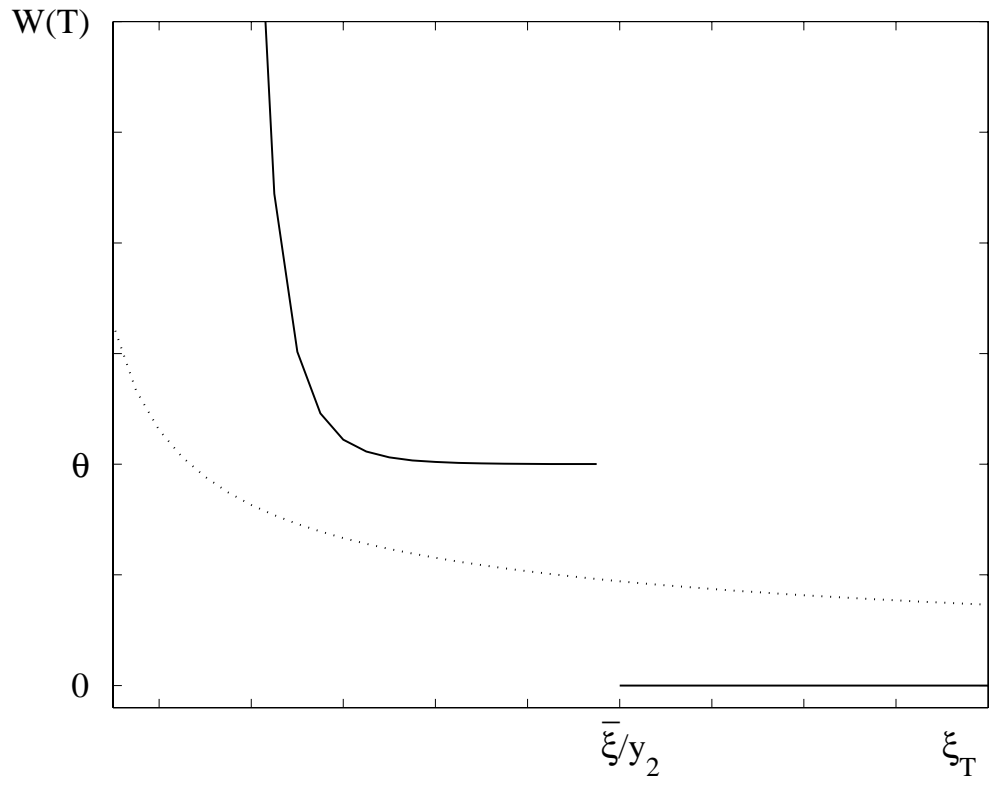

This figure shows the optimal terminal wealth in partial equilibrium for both groups of agents: loss averse agents (solid plot) and normal agents (dotted plot). Initial wealth equals $W(0)=1$ for both groups of agents. We assume power utility over consumption with risk aversion $\gamma=-1$. The scaling factors are $\rho_{1}=1$ and $\rho_{2}=10$. The other parameters used are $\gamma_{L}=\gamma_{G}=0.88, A=2.25, B=1.0$, and $\theta=1.0$. 
Figure 3: Optimal Fraction Invested in Stocks

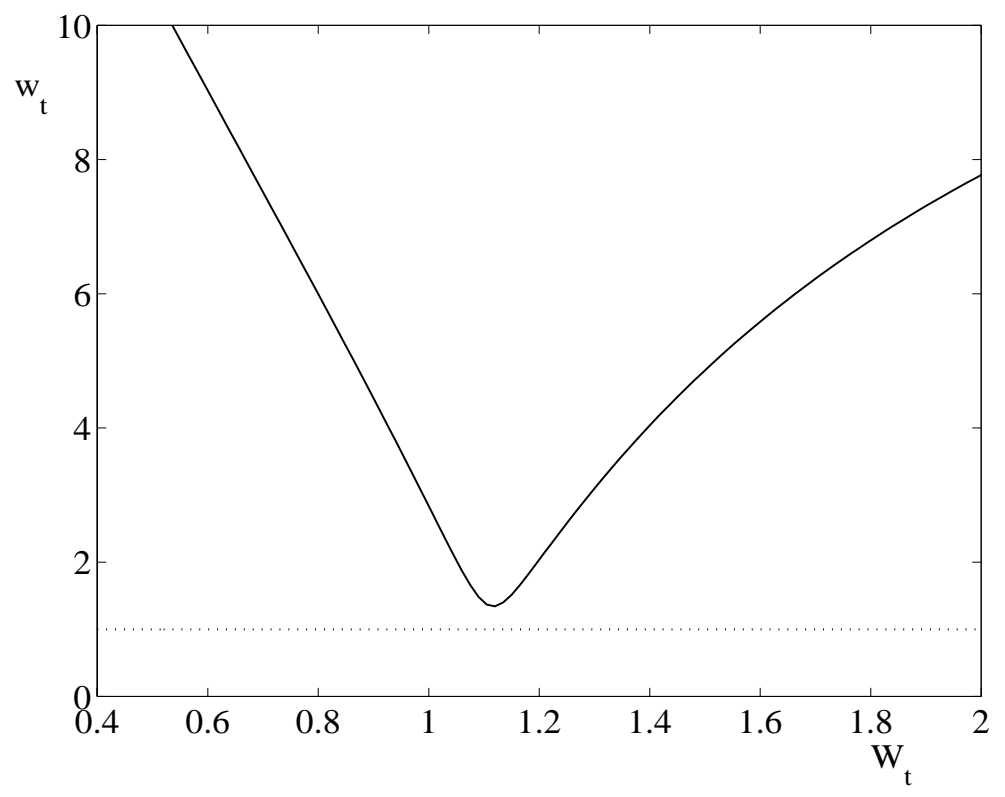

This figure shows the optimal fraction invested in stocks by a loss averse agent (solid plot) relative to the fraction invested by a normal agent (dotted plot), as a function of intermediate wealth. The parameters are the same as in Figure 2. The riskfree rate equals $r=0.072$, the Sharpe ratio is $\kappa=0.23$, the volatility equals $\sigma=0.115, t=0.5$ and $T=1$.

Figure 4: Equilibrium Stock Price

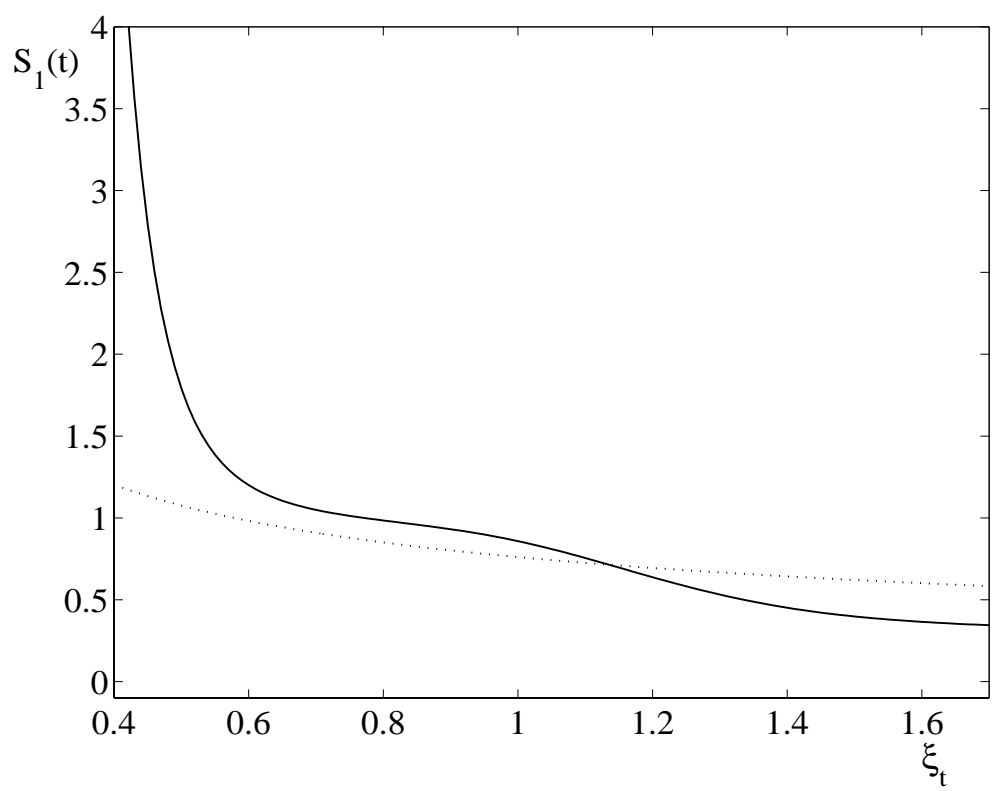

This figure shows the equilibrium stock price as a function of the pricing kernel in our economy with heterogeneous agents (solid plot) and the benchmark economy with normal agents only (dotted plot). Initial wealth equals $W_{i}(0)=1$ for both groups of agents. We assume power utility over consumption with risk aversion $\gamma=-1$. The scaling factors are $\rho_{1}=1$ and $\rho_{2}=10$. The other parameters used are $\lambda=0.5, \gamma_{L}=\gamma_{G}=0.88$, $A=2.25, B=1.0$, and $\theta=1.0$. Furthermore we assume $\mu_{\delta}=0.056$ and $\sigma_{\delta}=0.115$, and $t=0.5, T=1$. 
Figure 5: Equilibrium Drift Rate

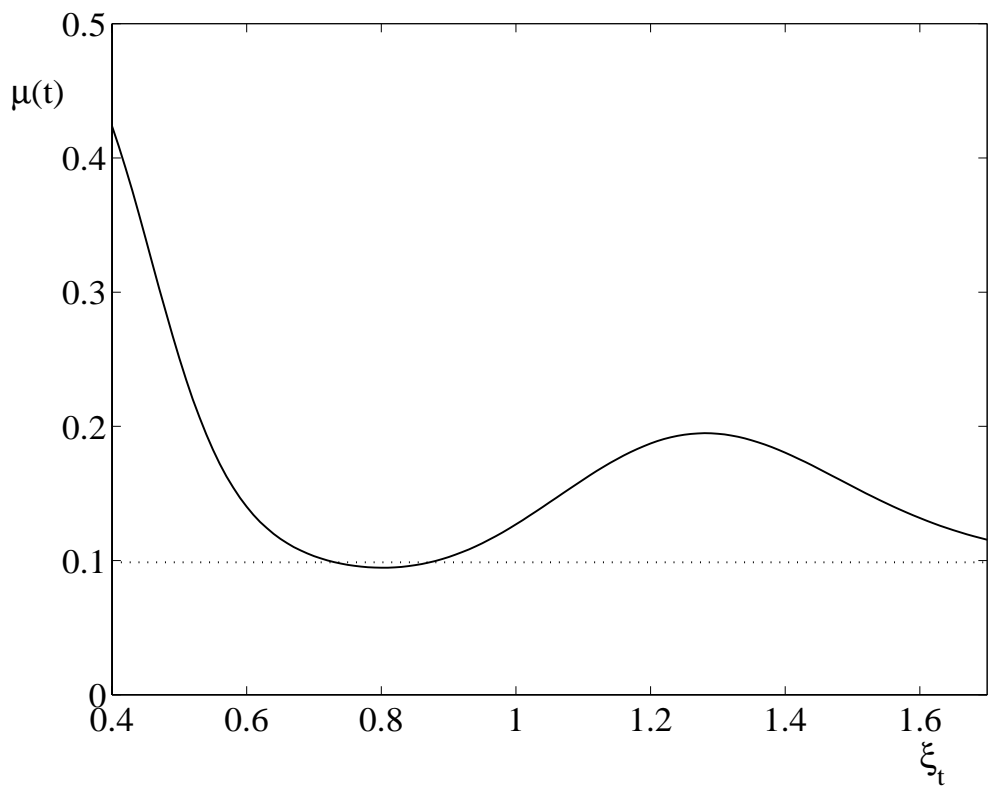

This figure shows the equilibrium drift rate of the stock price as a function of the pricing kernel in our economy with heterogeneous agents (solid plot) and the benchmark economy with normal agents only (dotted plot). The parameters are the same as in Figure 4.

Figure 6: Equilibrium Volatility

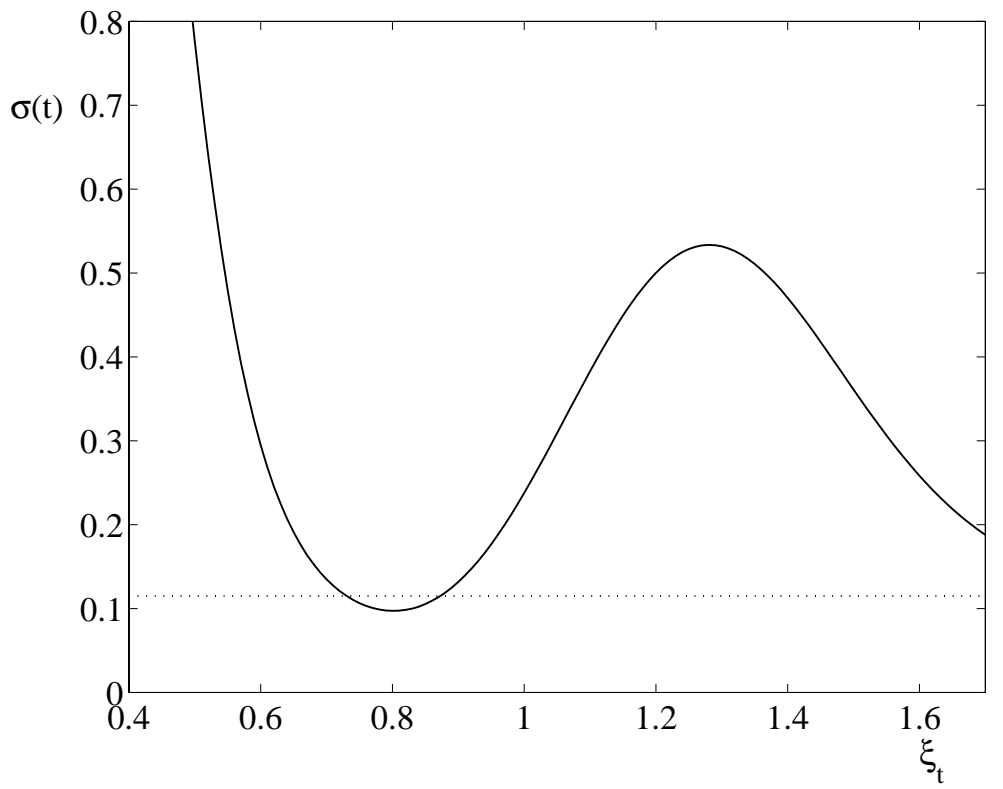

This figure shows the equilibrium volatility of the stock price as a function of the pricing kernel in our economy with heterogeneous agents (solid plot) and the benchmark economy with normal agents only (dotted plot). The parameters are the same as in Figure 4. 
Figure 7: Equilibrium Stock Price

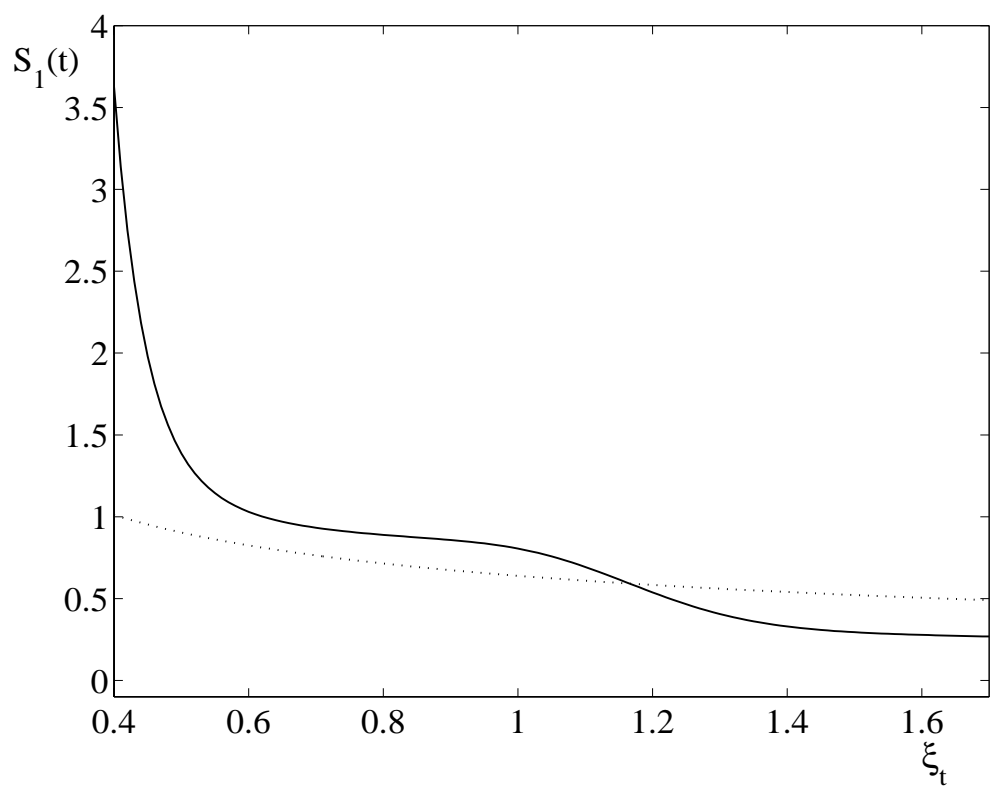

This figure shows the equilibrium stock price as a function of the pricing kernel in our economy with heterogeneous agents (solid plot) and the benchmark economy with normal agents only (dotted plot). The parameters are the same as in Figure 4, except that $t=0.75$.

Figure 8: Equilibrium Drift Rate as a Function of the Stock Price

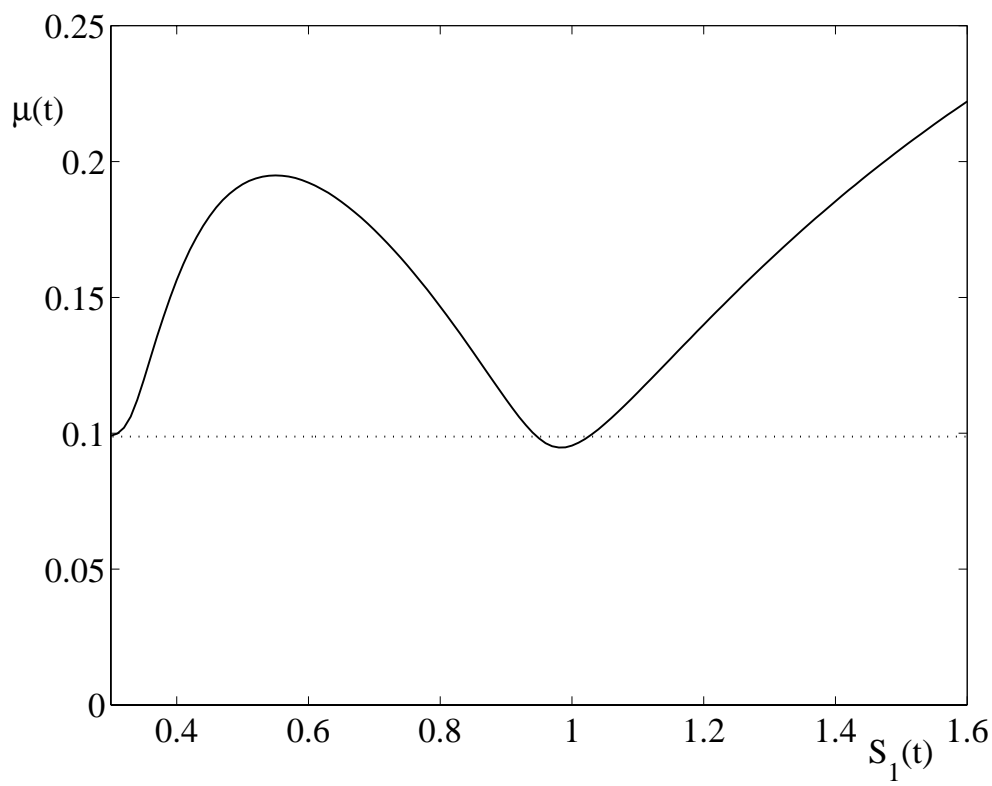

This figure shows the equilibrium drift rate as a function of the stock price in our economy with heterogeneous agents (solid plot) and the benchmark economy with normal agents only (dotted plot). The parameters are the same as in Figure 4. 
Figure 9: Equilibrium Stock Price with Heterogeneous Loss Averse Agents

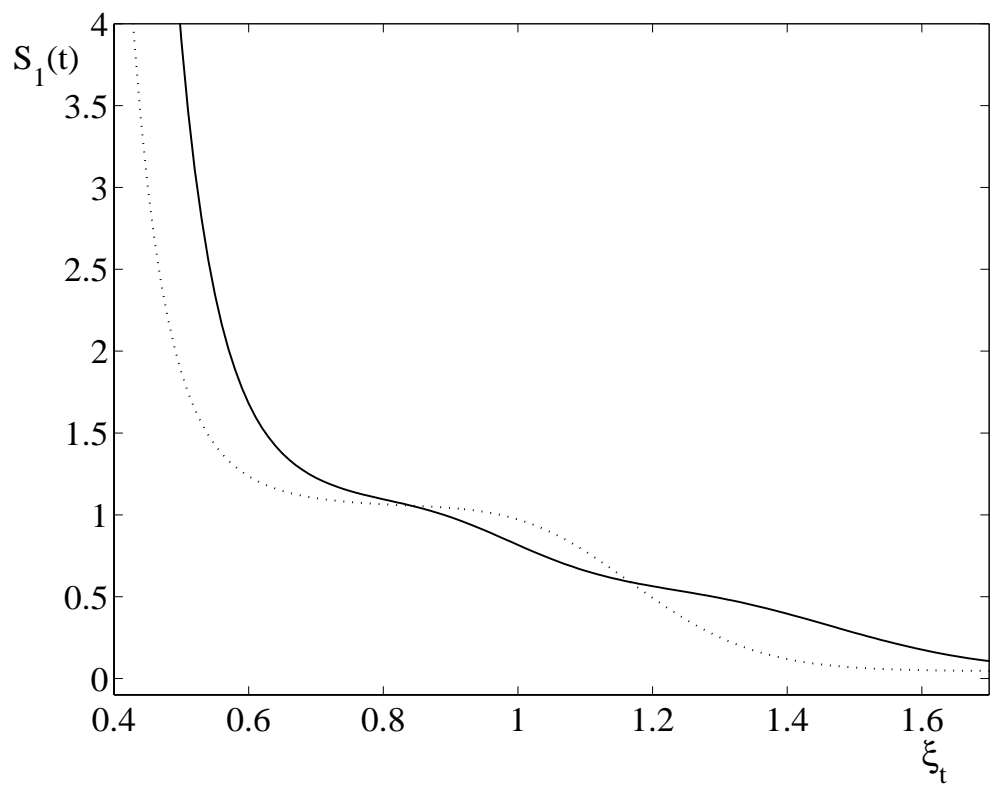

This figure shows the equilibrium stock price as a function of the pricing kernel in our economy with heterogeneous loss averse agents (solid plot) and an economy with one loss averse agent (dotted plot). The initial wealth of the agents in the heterogeneous economy are $W_{1}(0)=0.75$ and $W_{2}(0)=1.25$ respectively. The loss averse agent in the benchmark economy has initial wealth equal to 1.0. The other parameters are the same as in Figure 4, except that $t=0.75$ and $\varphi=0.5$.

Figure 10: Equilibrium Volatility with Heterogeneous Loss Averse Agents.

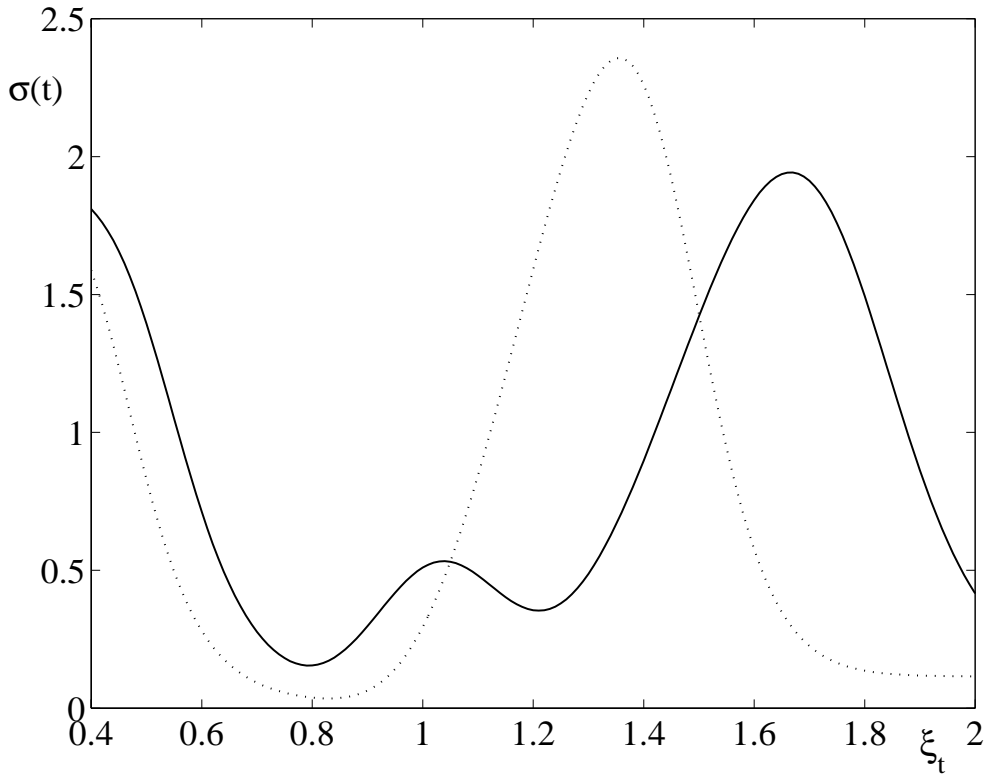

This figure shows the equilibrium volatility of the stock price as a function of the pricing kernel in our economy with heterogeneous loss averse agents (solid plot) and an economy with one loss averse agent (dotted plot). The initial wealth of the agents in the heterogeneous economy are $W_{1}(0)=0.75$ and $W_{2}(0)=1.25$ respectively. The loss averse agent in the benchmark economy has initial wealth equal to 1.0. The other parameters are the same as in Figure 9. 
Figure 11: Equilibrium Stock Price with Heterogeneous Loss Averse Agents

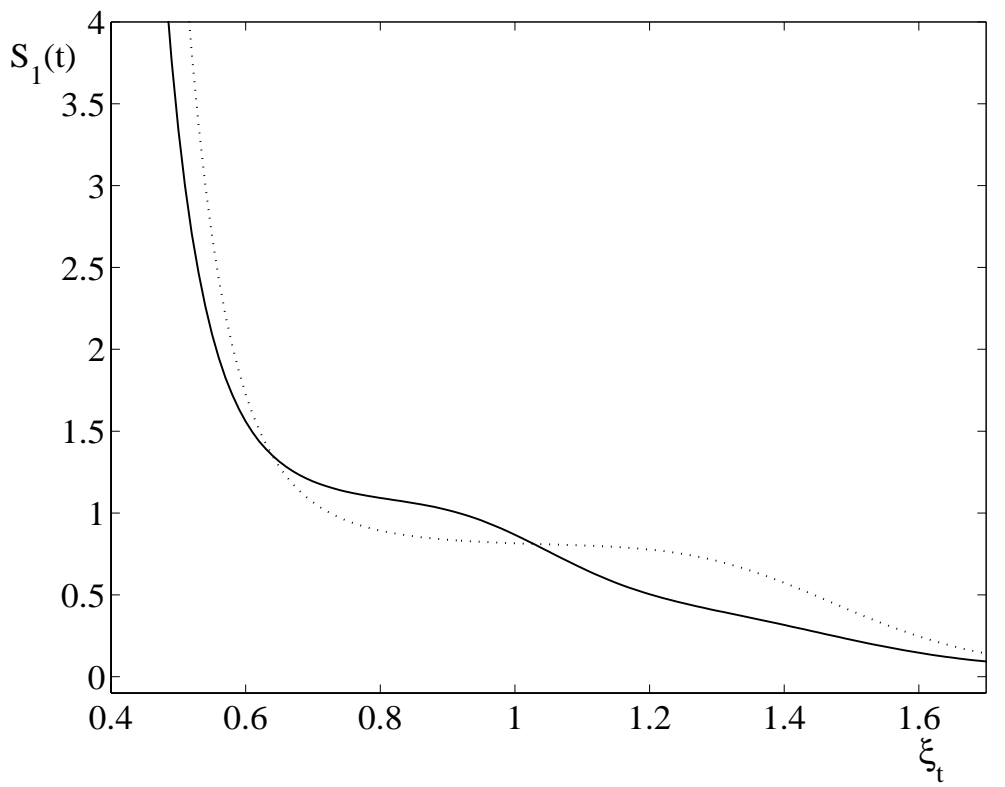

This figure shows the equilibrium stock price as a function of the pricing kernel in our economy with heterogeneous loss averse agents (solid plot) and an economy with one loss averse agent (dotted plot). The threshold of the agents in the heterogeneous economy are $\theta_{1}=1.25$ and $\theta_{2}=0.75$ respectively. The loss averse agent in the benchmark economy has a threshold equal to 1.0. The other parameters are the same as in Figure 9.

Figure 12: Initial Equity Premium as a Function of the Threshold

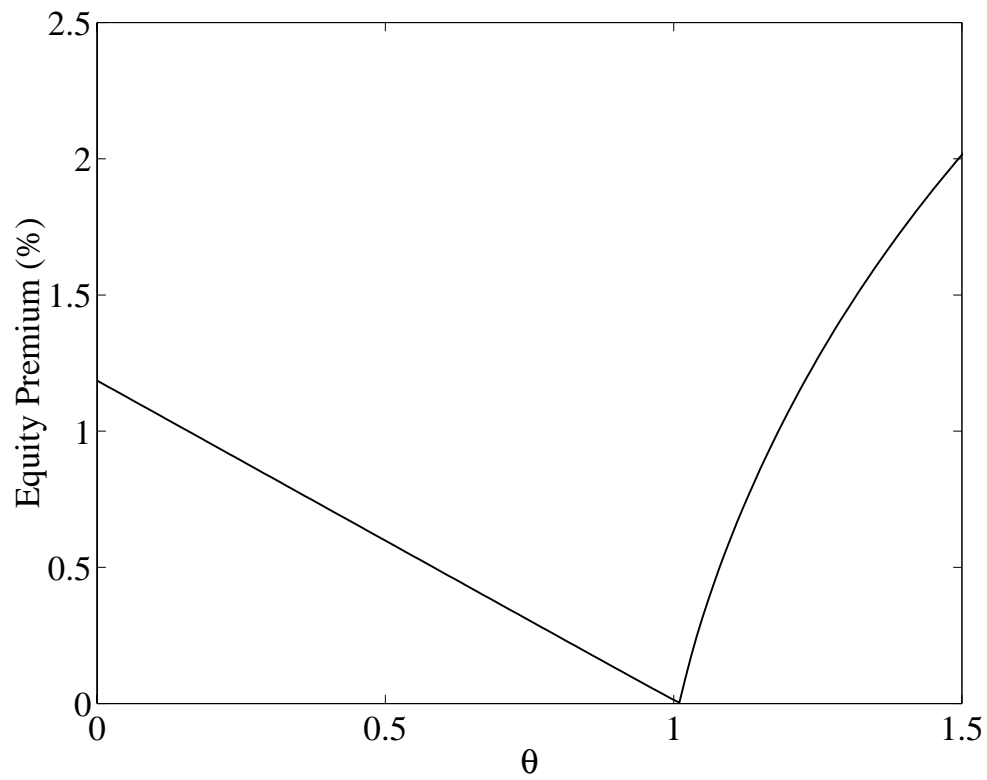

This figure shows the initial equity premium as a function of the threshold $\theta$ for a representative loss averse agent $(\lambda=0)$. We assume power utility over consumption with risk aversion $\gamma=0$. The scaling factor is $\rho_{2}=100$. The other parameters used are $\gamma_{L}=\gamma_{G}=0.88, A=2.25, B=1.0$, and $\theta=1.0$. Furthermore we assume $\mu_{\delta}=\mu_{c}=0.0184$ and $\sigma_{\delta}=\sigma_{c}=0.0379$, and $t=0, T=1$. 
Figure 13: Initial Volatility as a Function of the Threshold

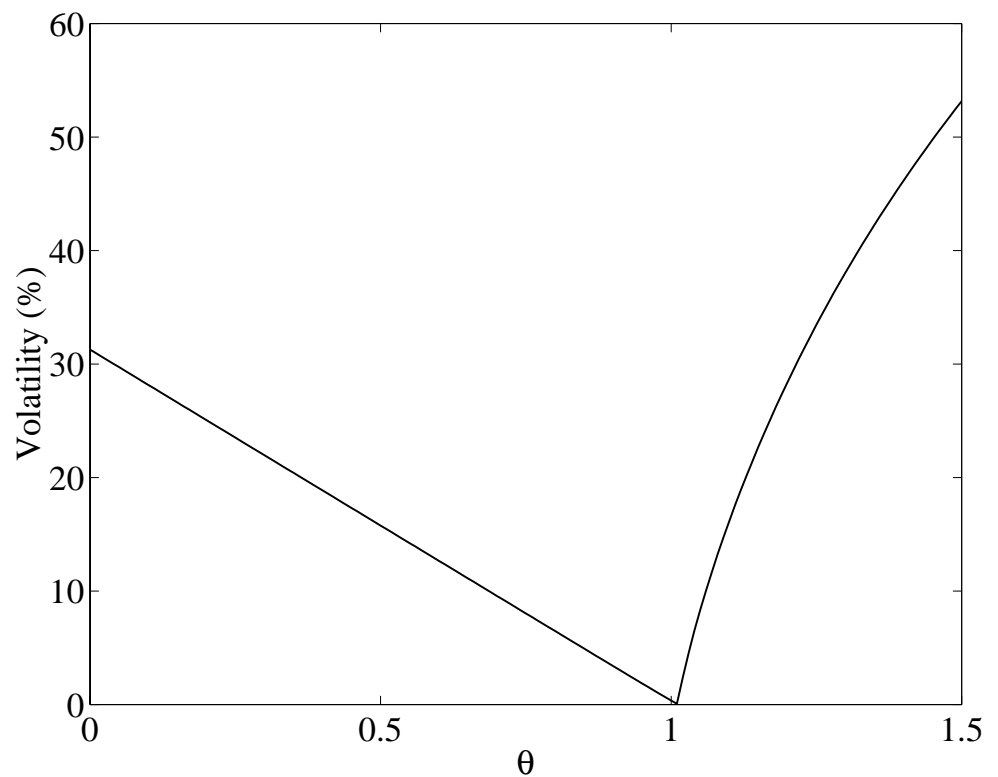

This figure shows the initial volatility as a function of the threshold $\theta$ for a representative loss averse agent. The parameters are the same as in Figure 12. 